\title{
Análise morfoanatômica comparativa de duas espécies de carqueja: Baccharis microcephala DC. e B. trimera (Less.) DC., Asteraceae
}

\author{
Jane Manfron Budel*, Márcia do Rocio Duarte \\ Laboratório de Farmacognosia, Departamento de Farmácia, Universidade Federal do Paraná
}

\begin{abstract}
A identificação de espécies de Baccharis que são constituídas de cladódios, ou seja, caules alados, apresenta dificuldades até mesmo para especialistas em taxonomia vegetal. Baccharis microcephala e $B$. trimera pertencem ao grupo Trimera e são conhecidas vulgarmente como carquejas. Na medicina popular, é comum o uso de espécies aladas para a aplicação terapêutica como diurético, hepatoprotetor e digestivo. Baccharis trimera consta na F. Bras. IV e possui atividades antiinflamatória, analgésica, bacteriostática, bactericida e antidiabética. As espécies B. trimera e B. microcephala são freqüentemente confundidas e utilizadas pela população para as mesmas finalidades terapêuticas. Objetivou-se estudar a morfologia externa e a anatomia dos cladódios dessas espécies, com a finalidade de se obterem dados que auxiliem na diferenciação e conseqüentemente na identificação das mesmas, contribuindo para o controle de qualidade de fitoterápicos, além de auxiliar na caracterização do grupo taxonômico. O material botânico foi submetido às microtécnicas fotônica e eletrônica de varredura usuais. As duas espécies são trialadas, sendo que em $B$. microcephala as alas são estreitas, praticamente contínuas em toda a extensão caulinar, enquanto que em $B$. trimera as alas são mais largas e interrompidas. As características morfológicas permitem a diferenciação dessas duas espécies, principalmente os tricomas tectores.
\end{abstract}

Unitermos: Asteraceae. Baccharis microcephala. Baccharis trimera. Controle de qualidade. Morfoanatomia.

The identification of Baccharis spp. which have cladodes, defined as winged stems, brings difficulties even for taxonomists. Baccharis microcephala and B. trimera belong to the Trimera group and are known as carquejas. In folk medicine, it is common the use of winged species for the same therapeutic indication, such as diuretic, hepatoprotective and digestive. The monograph of $B$. trimera is included in the F. Bras. IV and this species shows anti-inflammatory, analgesic, bacteriostatic, bactericidal and antidiabetic activities. The species B. trimera and B. microcephala are alike and used by the population for the same therapeutic purposes. This work has aimed to study the external morphology and anatomy of the cladodes of these species, in order to contribute to the quality control of phytotherapic agents, as well as supply information for the taxonomic group. The botanical material was prepared for light and scanning electron microtechniques. Both species are three-winged, although the stem wings are narrow and nearly continuous in B. microcephala while in B. trimera they are wider and interrupted. The morphological characters and mainly the non-glandular trichomes allow these species to be distinguished.

Uniterms: Asteraceae. Baccharis microcephala. Baccharis trimera. Morpho-anatomy. Quality control.

\section{INTRODUÇÃO}

O gênero Baccharis pertence à tribo Astereae e à

\footnotetext{
*Correspondência: J. M. Budel. Departamento de Farmácia, Universidade Federal do Paraná - UFPR, Av. Lothário Meissner, 632, Jd. Botânico 80210-170 - Curitiba - PR, Brasil. E-mail: janemafron@hotmail.com
}

subtribo Baccharidinae e inclui cerca de 400 espécies que habitam desde os Estados Unidos até a Argentina (ArizaEspinar, 1973; Judd et al., 1999). Extratos de várias espécies de Baccharis têm demonstrado ação farmacológica (Budel et al., 2008), como antiinflamatório, antimicrobiano, antiviral (HIV) e gastroprotetor (Cifuente et al., 2001; Feresin et al., 2001; Sanchez-Palomino et al., 2002; 
Baggio et al., 2003; Abad et al., 2006) e atividade antioxidante também tem sido relatada para o táxon (Oliveira et al., 2003; Tapia et al., 2004; Rosas-Romero, Saavedra 2005; Simões-Pires et al., 2005; Budel et al., 2008).

A identificação desse grupamento vegetal é complexa entre as espécies de caules alados, as carquejas. Esse fato acarreta o uso indiscriminado para a mesma finalidade terapêutica, devido à utilização da mesma sinonímia popular para diferentes espécies. A problemática da caracterização botânica é relatada inclusive por especialistas no gênero (Watanabe et al., 2005). Barroso e Bueno (2002) e Alonso e Desmarchelier (2006) afirmam que $B$. trimera (Less.) DC. é muito confundida com B. crispa Spreng., B. microcephala DC., B. stenocephala Baker e B. usterii Heering. Neste sentido, a morfoanatomia de espécies de Baccharis tem sido investigada (Sá, Neves, 1996; Chicourel et al., 1997; Oliveira, Bastos, 1998; Cortadi et al., 1999; Gianello et al., 2000; Ortins, Akisue, 2000; Budel et al., 2003a, b; Budel et al., 2004a, b), com o objetivo de fornecer subsídios que auxiliem na identificação de drogas vegetais.

Bueno e Barroso (2002) dividiram o gênero em 28 grupos com a finalidade de reunir espécies morfologicamente próximas em unidades mais amplas e, entre estes, está o grupo Trimera que compreende espécies com cladódios, a exemplo de $B$. trimera e $B$. microcephala, que são utilizadas popularmente como digestivo, diurético e hepatoprotetor (Ariza-Espinar, 1973; Corrêa, 1984; Barroso, Bueno, 2002; Alonso, Desmarchelier, 2006). Na indústria de fitoterápicos, as carquejas fazem parte principalmente de fórmulas emagrecedoras (Bona et al., 2002).

Baccharis trimera é a espécie mais estudada farmacologicamente dentre todas as carquejas (Budel et al., 2005) e consta da F. Bras. IV (1988-2003). Estudos químicos revelaram a presença de flavonóides como quercetina, luteolina, nepetina, apigenina e hispidulina (Soike, Leng-Peschlow, 1987), saponinas, lactonas sesquiterpênicas (Mors et al., 2000; Alonso, Desmarchelier, 2006) e taninos (Bianchi et al., 1993). No óleo essencial foram encontrados $\alpha$-pineno, $\beta$-pineno, carquejol, acetato de carquejila, canfeno e nopineno (Siqueira et al. 1985; Mors et al., 2000; Simões-Pires et al., 2005). Baccharis trimera apresenta ações farmacológicas, como atividades moluscicida (Santos-Filho et al., 1980), hepatoprotetora (Soicke, Leng-Peschlow, 1987), antiinflamatória (Gene et al., 1992), analgésica (Gene et al., 1996), bacteriostática, bactericida (Avancini et al., 2000), antiproteolítica, anti-hemorrágica contra veneno de cobra (Januário et al., 2004) e antidiabética (Oliveira et al., 2005). Baccharis microcephala contém alcalóides, flavonóides, triterpenos e saponinas (Bianchi et al., 1993).
O estudo da morfologia externa e da anatomia dos cladódios de B. microcephala e de B. trimera tem por objetivos auxiliar na identificação dessas duas espécies, detectar características de importância taxonômica para o grupo Trimera e contribuir para o controle de qualidade de fitoterápicos.

\section{MATERIAL E MÉTODOS}

\section{Material botânico}

Caules alados, obtidos de 5 a $15 \mathrm{~cm}$ do ápice caulinar, foram coletados de pelo menos cinco espécimes de $B$. trimera na Região Metropolitana de Curitiba $\left(25^{\circ} 25^{\prime} \mathrm{S}\right.$ e $49^{\circ} 16^{\prime} \mathrm{W}, 930$ m de altitude), Paraná, Brasil, em setembro de 2003, e B. microcephala foi coletada na Fazenda São Maximiano ( $30^{\circ} 10^{\prime} \mathrm{S}$ e $51^{\circ} 20^{\prime} \mathrm{W}, 27 \mathrm{~m}$ de altitude), Guaíba, Rio Grande do Sul, Brasil, em dezembro de 2003. O material florido foi identificado pelo taxonomista Dr. Nelson Ivo Matzenbacher, professor do Programa de Pósgraduação em Botânica da UFRGS, e os representantes equivalentes estão depositados no Herbário do Instituto de Ciências Naturais da Universidade Federal do Rio Grande do Sul, sob registro ICN - No 49294 para B. microcephala e ICN - No 129479 para B. trimera.

\section{METODOLOGIA}

A fixação dos cladódios foi realizada utilizando-se FAA 70 (Johansen, 1940) e álcool etílico a 70\% como solução de estoque (Berlyn, Miksche, 1976).

Foram preparadas lâminas semipermanentes com o material seccionado nos sentidos transversal e longitudinal, à mão livre, submetido à coloração de azul de astra e fucsina básica (Roeser, 1972) ou de azul de toluidina (O’Brien et al., 1964), e montado com glicerina diluída a 50\% (Berlyn, Miksche, 1976).

Para a preparação das lâminas permanentes, utilizou-se a técnica de inclusão em glicol metacrilato (Feder, O'Brien, 1968). Empregou-se o material previamente fixado e armazenado em álcool etílico a 70\%. O material foi seccionado no plano transversal em micrótomo rotativo, obtendo-se cortes de 7 a $9 \mu \mathrm{m}$. Os cortes foram hidratados, distendidos em lâminas e secos em mesa térmica a $40^{\circ} \mathrm{C}$. Para a coloração foi utilizado azul de astra-fucsina básica (Brito, Alquini, 1996) e o meio de montagem empregado foi Entellan ${ }^{\circledR}$.

Os reativos empregados para os testes histoquímicos foram: solução de floroglucina clorídrica para verificação de lignina (Foster, 1949), Sudan III para compostos lipofílicos (Sass, 1951), cloreto férrico para compostos 
fenólicos (Johansen, 1940), lugol para amido (Berlyn, Miksche, 1976) e ácido sulfúrico para verificação da natureza química dos cristais (Oliveira, Akisue, 1997).

Foi realizada a análise ultra-estrutural de superfície (microscopia eletrônica de varredura-MEV) (Souza, 1998) em alto vácuo. Para tal procedimento, as amostras foram desidratadas em série etanólica crescente e pelo ponto crítico de $\mathrm{CO} 2$ e, após montagem em suporte, submetidas à metalização com ouro. Também foram utilizadas representações diagramáticas para ilustrar a organização interna das espécies.

\section{RESULTADOS}

\section{Análise morfológica externa}

Baccharis microcephala (Figura 1) apresenta caule alado medindo 0,5 a $1,0 \mathrm{~m}$ de altura e se diferencia em cladódios com 3 projeções. O eixo central do cladódio é lenhoso e acompanhado por 3 alas descontínuas e estreitas, com aproximadamente 1,0 a 3,0 $\mathrm{mm}$ de largura.

Baccharis trimera (Figura 2) atinge 0,5 a 1,0 m de altura, com 3 alas descontínuas e mais largas, medindo cerca de 0,5 a $1,3 \mathrm{~cm}$ de largura.

As alas de B. microcephala (Figura 3) e B. trimera (Figura 4) se dispõem de modo eqüidistante no eixo caulinar. As duas espécies, em vista frontal, apresentam células epidérmicas com contorno poligonal (Figuras 5, 6). Em secção transversal, a epiderme mostra-se uniestratificada

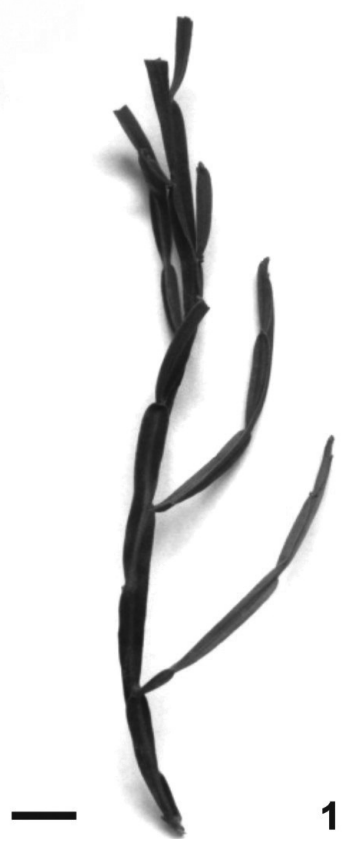

FIGURA 1 - Baccharis microcephala DC. - Ramo reprodutivo. Barra $=2 \mathrm{~cm}$.

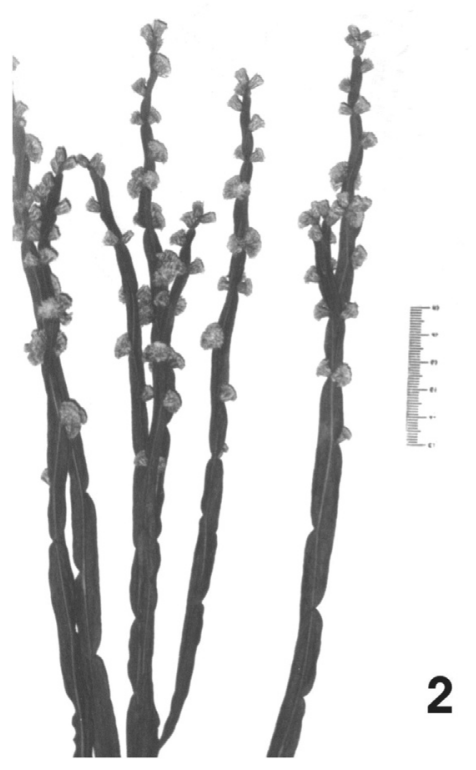

FIGURA 2 - Baccharis trimera (Less.) DC. - Ramos reprodutivos e vegetativos.

(Figura 7) e revestida por cutícula delgada. A ornamentação cuticular nas duas espécies é levemente estriada, como observado em MEV (Figura 9).

Ambas as espécies apresentam estômatos anisocíticos (Figura 6) e anomocíticos (Figuras 5, 6) e estes estão localizados no mesmo nível (Figura 6) ou ligeiramente acima das demais células epidérmicas. Em B. microcephala são encontrados 2 tipos de tricomas: glandular pluricelular bisseriado (Figura 11), que reage positivamente à pesquisa de compostos lipofílicos, e tector unisseriado, com pedicelo formado por 3-4 células e com célula apical alongada e afilada (Figuras 8,12) e de paredes espessadas não-lignificadas. Em $B$. trimera é observado tricoma

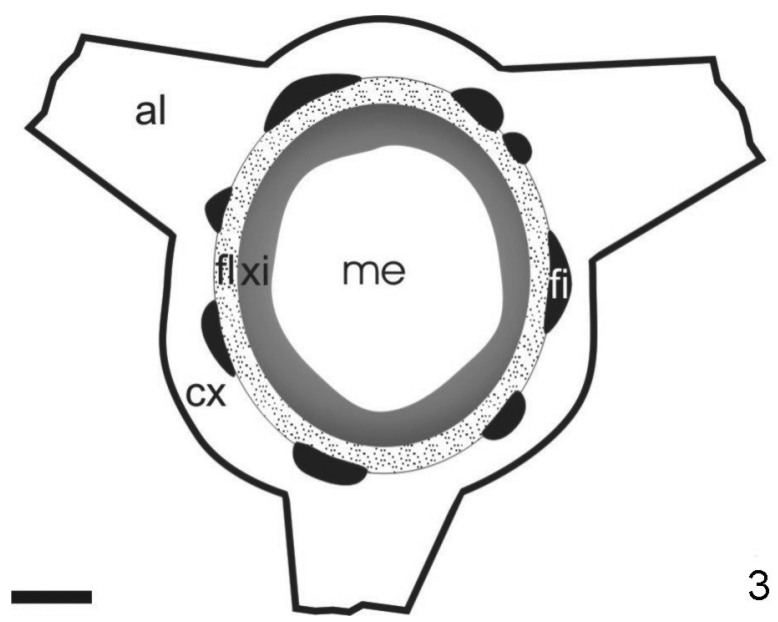

FIGURA 3 - B. microcephala-Diagrama da secção transversal do cladódio. al: ala; cx: córtex; fi: fibras esclerenquimáticas; fl: floema; me: medula; xi: xilema. Barra $=100 \mu \mathrm{m}$. 


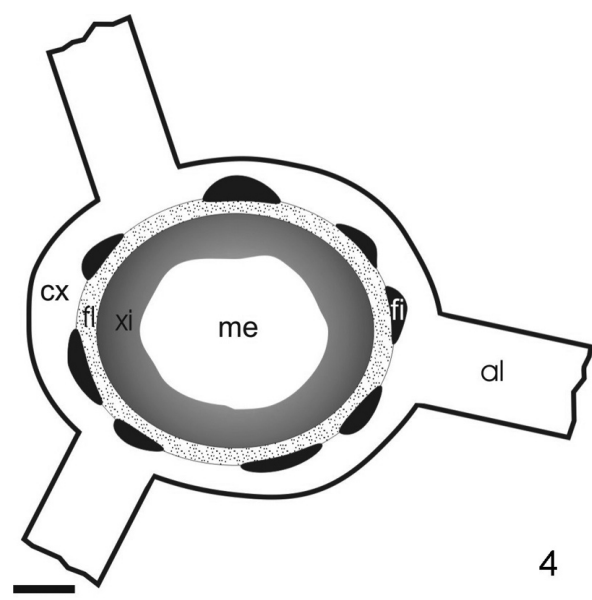

FIGURA 4 - B. trimera - Diagrama da secção transversal do cladódio. al: ala; cx: córtex; fi: fibras esclerenquimáticas; fl: floema; me: medula; xi: xilema. Barra $=100 \mu \mathrm{m}$.

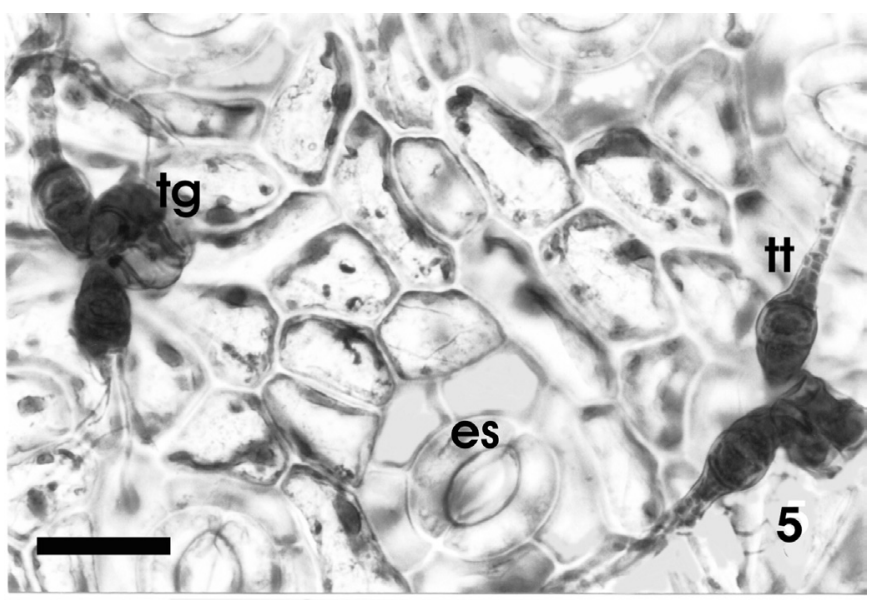

FIGURA 5 - B. microcephala - Vista frontal da epiderme da ala dos cladódios. es: estômato; tg: tricoma glandular; tt: tricoma tector. Barra $=20 \mu \mathrm{m}$.

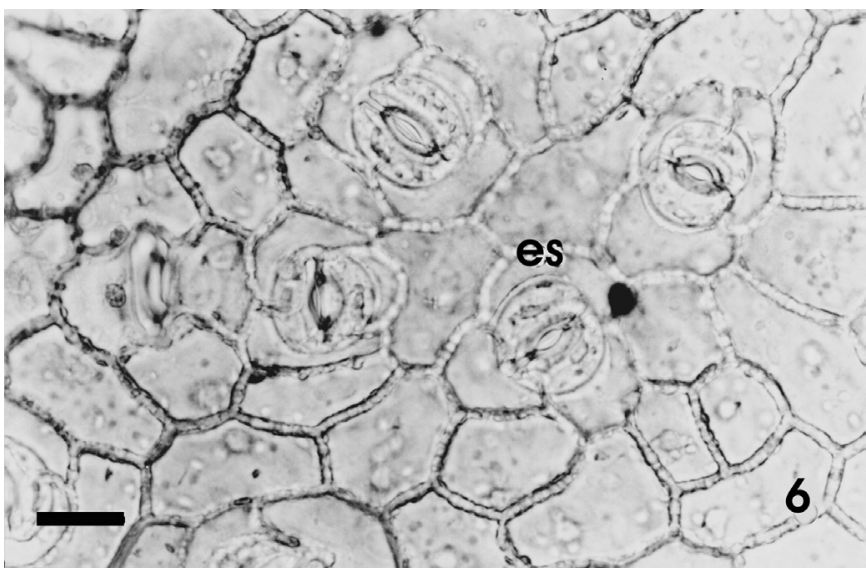

FIGURA 6 - B. trimera - Vista frontal da epiderme da ala dos cladódios. es: estômato. Barra $=20 \mu \mathrm{m}$.

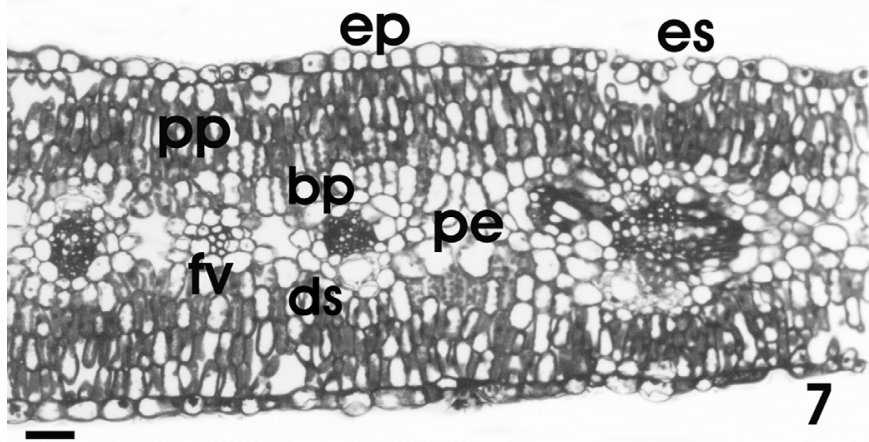

FIGURA 7 - B. microcephala - Secção transversal da ala do cladódio. bp: bainha parenquimática; ds: duto secretor; ep: epiderme; es: estômato; fv: feixe vascular; pe: parênquima esponjoso; pp: parênquima paliçádico. Barra $=50 \mu \mathrm{m}$.

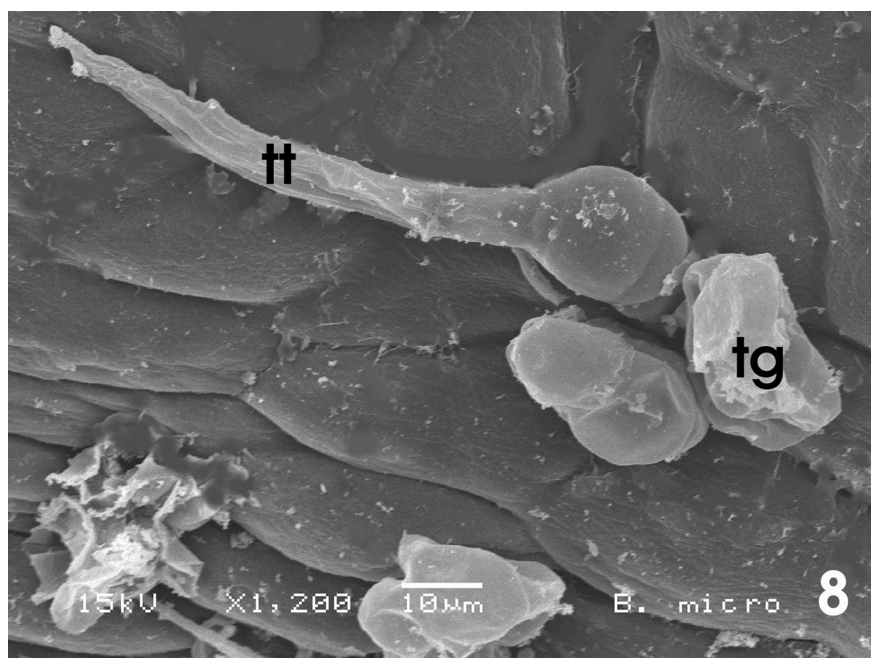

FIGURA 8 - B. microcephala - Vista frontal da epiderme do cladódio (MEV). tg: tricoma glandular; tt: tricoma tector.

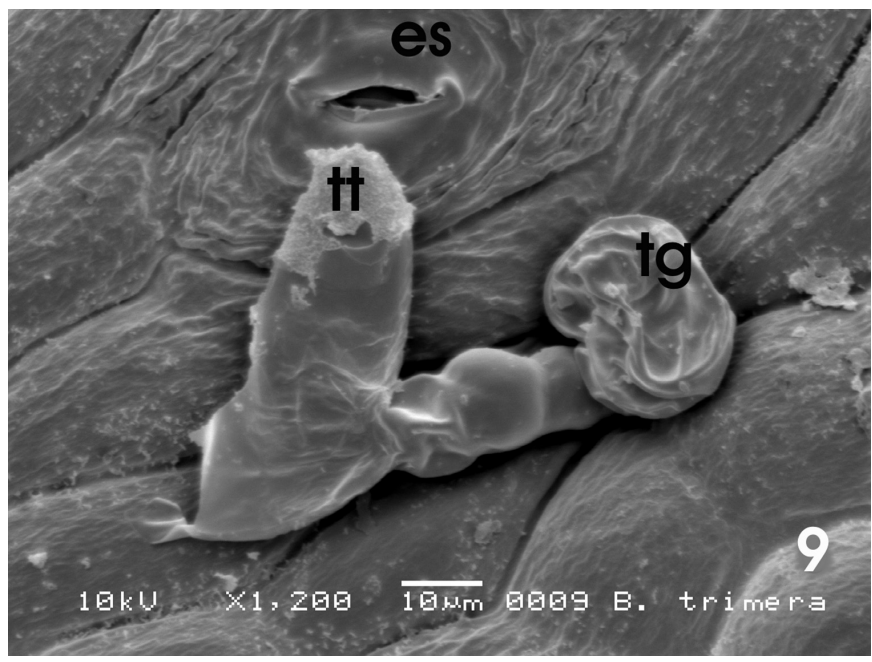

FIGURA 9-B. trimera - Vista frontal da epiderme do cladódio (MEV). es: estômato; tg: tricoma glandular; tt: tricoma tector. 
glandular (Figura 9) pluricelular bisseriado e um tipo de tricoma tector pluricelular com 5 células na base e a célula apical afilada, periclinalmente alongada e em forma de $\mathrm{T}$ (Figura 13).

O clorênquima, em disposição heterogênea assimétrica, diferencia-se em parênquima paliçádico atípico, com células relativamente curtas formando 3 ou 4 estratos, de alturas semelhantes, em posição adjacente às faces da epiderme; e em parênquima esponjoso na região mediana, cujas células formam pequenos espaços intercelulares. Os feixes vasculares são colaterais, envoltos por bainha parenquimática e distribuídos no parênquima esponjoso (Figura 7). Próximo à bainha parenquimática e na região da borda

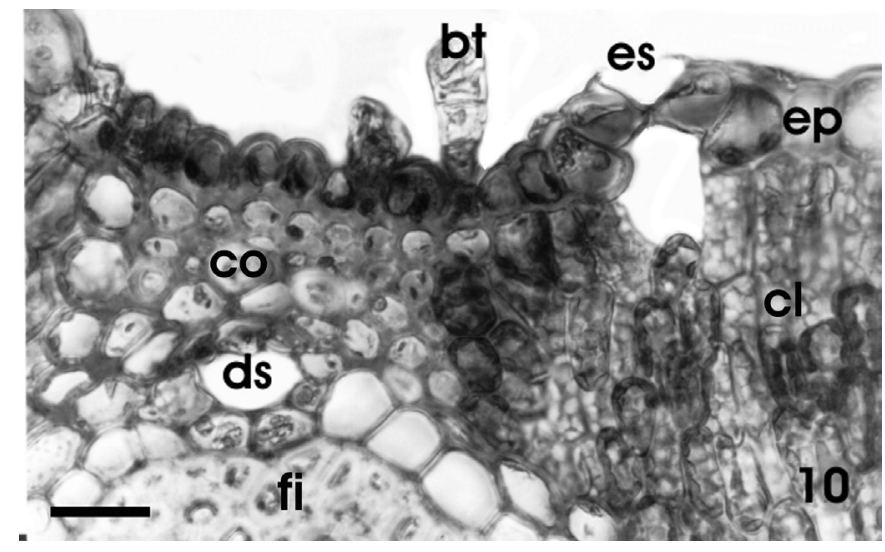

FIGURA 10 - B. microcephala - Detalhe do eixo caulinar, em secção transversal. bt: base de tricoma; cl: clorênquima; co: colênquima; ds: duto secretor; ep: epiderme; es: estômato; fi: fibras esclerenquimáticas. Barra $=20 \mu \mathrm{m}$.

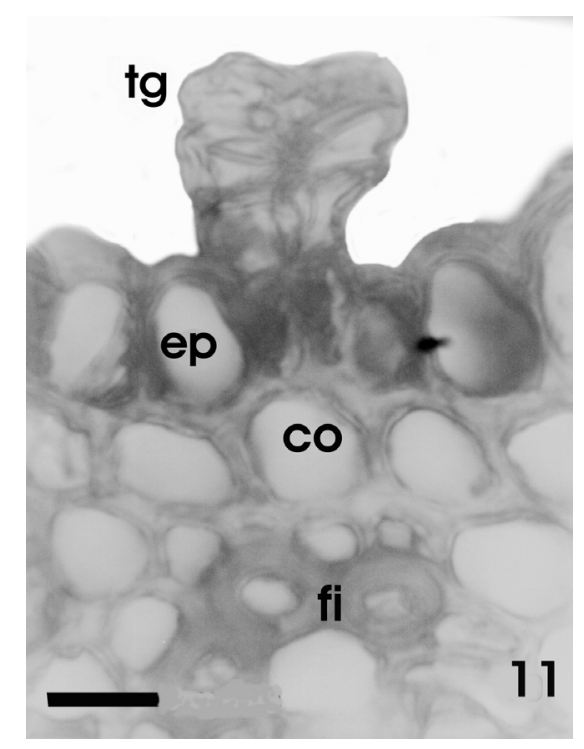

FIGURA 11 - B. microcephala - Detalhe do eixo caulinar, em secção transversal. co: colênquima; ep: epiderme; fi: fibras esclerenquimáticas; tg: tricoma glandular bisseriado. Barra = $10 \mu \mathrm{m}$.

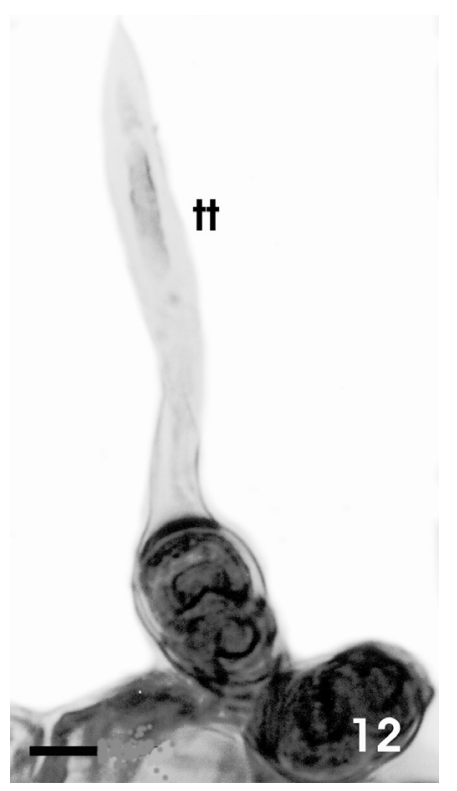

FIGURA $12-$ B. microcephala - Detalhe do tricoma tector $(\mathrm{tt})$. Barra $=10 \mu \mathrm{m}$.

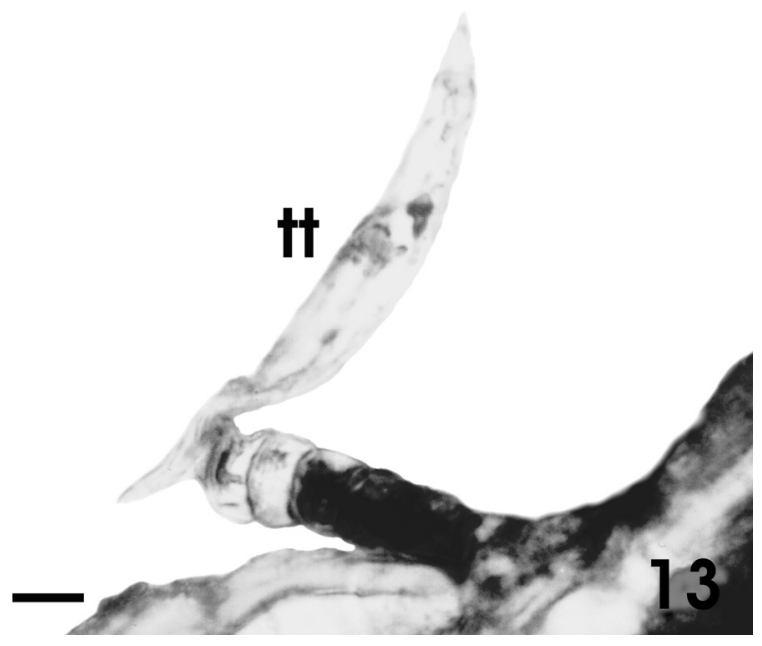

FIGURA 13 - B. trimera - Detalhe do tricoma tector (tt). Barra $=10 \mu \mathrm{m}$.

das alas é comum a ocorrência de um ou mais dutos secretores (Figura 7), que apresentam epitélio unisseriado formado por cerca de 6-10 células, com citoplasma denso, núcleo evidente e secretam produto de natureza lipofílica. A região da borda é preenchida por fibras (Figura 14).

O eixo caulinar de $B$. microcephala e $B$. trimera, em secção transversal, tem contorno circular (Figuras 3 e 4) e, de maneira geral, a estrutura interna revela-se semelhante nas 2 espécies.

A epiderme mostra as mesmas características observadas nas alas dos cladódios. Subjacente ao sistema de revestimento encontram-se cordões alternados de clorênquima e colênquima do tipo angular (Figura 10). 


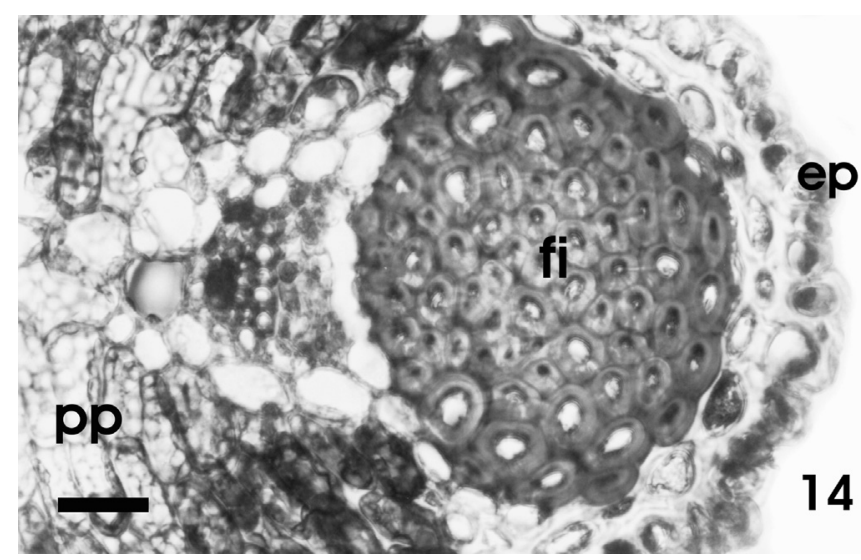

FIGURA 14 - B. trimera - Borda da ala do cladódio, em secção transversal. ep: epiderme; fi: fibras esclerenquimáticas; pp: parênquima palicádico. Barra $=20 \mu \mathrm{m}$.

Este, na direção dos feixes vasculares, apresenta cerca de 3 estratos.

Dutos secretores similares aos das alas são encontrados nas proximidades da bainha parenquimática (Figura 15), que delimita internamente a região cortical, e cujas paredes celulares apresentam impregnações de compostos lipofílicos.

O sistema vascular é constituído por um cilindro de floema, formado em direção centrífuga, e um cilindro de xilema, formado centripetamente, estabelecendo uma região medular. Calotas de fibras perivasculares são encontradas apostas ao floema (Figura 15).

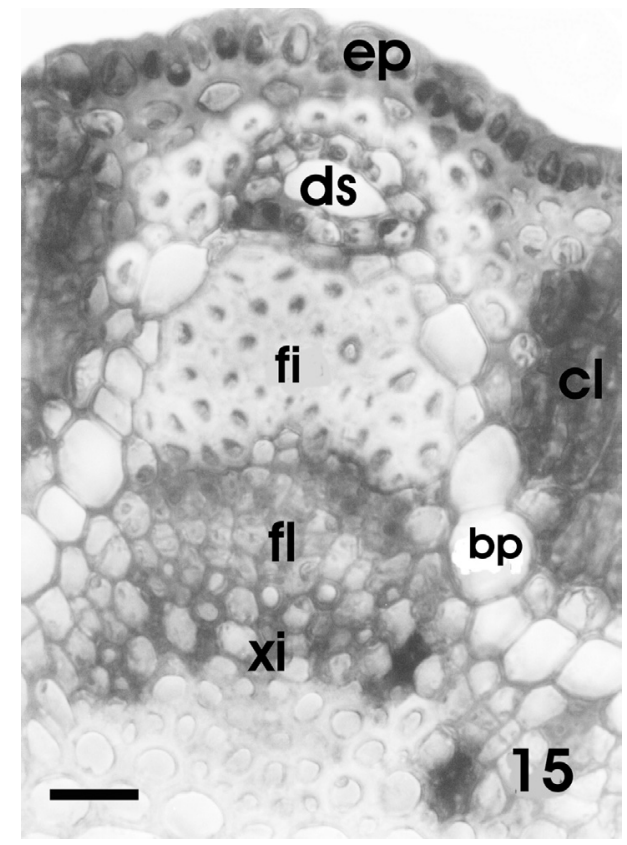

FIGURA 15 - B. trimera - Detalhe parcial do eixo do cladódio, em secção transversal. cl: clorênquima; ds: duto secretor; bp: bainha parenquimática; ep: epiderme; fi: fibras esclerenquimáticas; fl: floema; xi: xilema. Barra $=20 \mu \mathrm{m}$.
O parênquima medular das duas espécies compõe-se de células de diversos tamanhos e de paredes delgadas, e na zona perimedular são encontrados cristais de oxalato de cálcio de diferentes dimensões, predominantemente piramidais em $B$. microcephala (Figura 16) e piramidais e prismáticos de diversos tamanhos em $B$. trimera (Figura 17).

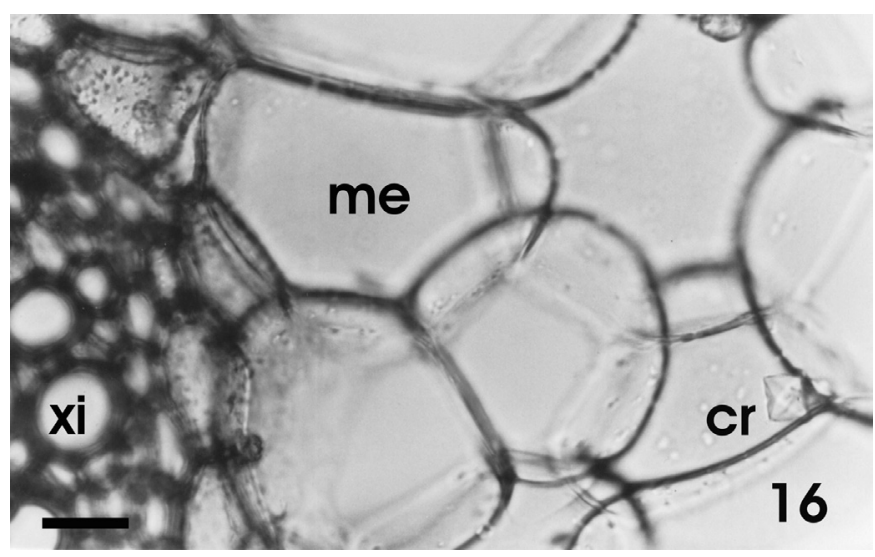

FIGURA 16 - B. microcephala - Detalhe da região perimedular, em secção transversal. cr: cristais de oxalato de cálcio piramidais; me: medula; xi: xilema. Barra $=20 \mu \mathrm{m}$.

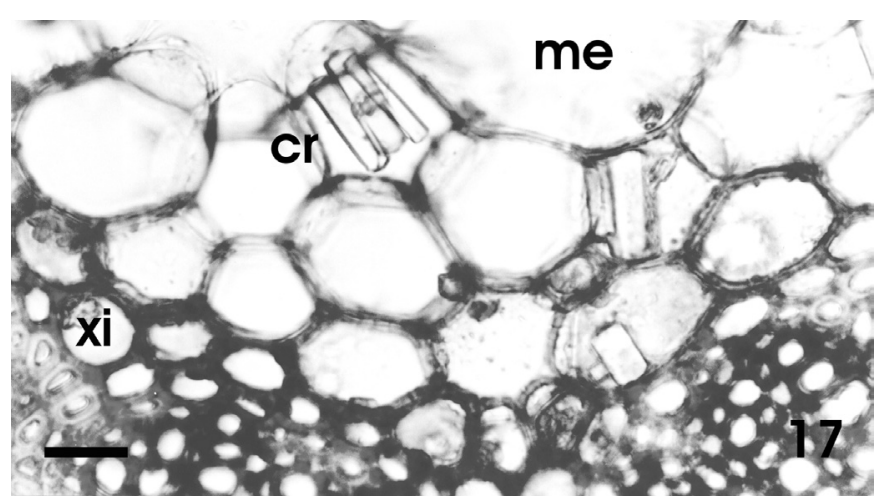

FIGURA 17 - B. trimera - Detalhe da região perimedular, em secção transversal. cr: cristais de oxalato de cálcio prismáticos de diferentes dimensões; me: medula; xi: xilema. Barra $=20$ $\mu \mathrm{m}$.

\section{DISCUSSÃO}

Para Baccharis trimera, a F. Bras. IV (1988-2003) descreve a presença de raras folhas sésseis, enquanto que Barroso e Bueno (2002) indicam que folhas ovais muito reduzidas são encontradas nessa espécie. Neste estudo não foram observados esses órgãos nas espécies analisadas. Baccharis microcephala e $B$. trimera mostram caules trialados, dado este que vai ao encontro das características das espécies representantes do grupo Trimera (Ariza-Espinar, 1973; Barroso, 1976; Barroso, Bueno, 2002). Adicional- 
mente, a F. Bras. IV (1988-2003) descreve para B. trimera a presença de costelas pronunciadas entre as alas, o que não foi observado.

Monteiro et al. (2001) relatam que a descrição de tricomas glandulares de Asteraceae contribui para elucidar questões taxonômicas e filogenéticas. Tricomas glandulares bisseriados têm sido freqüentemente encontrados em diferentes tribos de Asteraceae como Anthemideae, Astereae, Eupatorieae, Heliantheae, Inuleae, Mutisieae e Vernonieae (Ariza-Spinar, 1973; Rodriguez et al., 1984; Castro et al., 1997; Cortadi et al., 1999; Monteiro et al., 2001). No estudo em questão, B. microcephala e B. trimera apresentam tricoma glandular pluricelular bisseriado. Esse tipo de tricoma também foi encontrado em $B$. sessiliflora Vahl (Castro et al., 1997), B. articulata (Lam.) Pers., $B$. crispa Spreng. (Cortadi et al., 1999) e B. trimera (Cortadi et al., 1999; F. Bras. IV, 1988-2003). Rodriguez et al. (1984) e Fahn (1988) relatam a presença de diversos conteúdos em tricomas glandulares, como plastídeos, cristais, fenóis, proteínas, enzimas, polissacarídeos e substâncias lipofílicas, tais como óleos essenciais, gorduras e resinas. Adicionalmente, Castro et al. (1997) e Monteiro et al. (2001) afirmam que o material de secreção, liberado pelas células da porção terminal desses tricomas, é armazenado na cavidade do tricoma denominada espaço subcuticular que se forma pela distensão da cutícula.

Segundo Werker (2000), tricomas tectores são diferentes na morfologia, anatomia e microestrutura, contudo são basicamente distintos pela morfologia resultando em diversas descrições, como estrelado, em forma de $\mathrm{T}$, dendrítico, em forma de escama, felpudo, espinhento, em forma de anzol, espiralado, entre outros. Para muitas espécies do gênero Baccharis, Ariza-Espinar (1973) descreve tricomas tectores pluricelulares unisseriados com base formada de 2-8 células, diferindo quanto à morfologia da célula apical, que pode ser medianamente alongada até assumir a forma de chicote. Tricomas similares foram relatados em B. articulata (Ariza-Espinar, 1973; Cortadi et al., 1999; Ortins, Akisue, 2000), B. gaudichaudiana DC. (Budel et al., 2003), B. grisebachii Hieron (ArizaEspinar, 1973), B. myriocephala DC. (Sá, Neves, 1996), B. mesoneura DC. (Barroso, 1976) e B. trimera (Chicourel et al., 1997; Cortadi et al., 1999).

Baccharis trimera evidencia tricoma tector pluricelular, unisseriado, com 5 células na base e a célula apical afilada, periclinalmente alongada e em forma de $\mathrm{T}$, enquanto que em $B$. microcephala foi observado tector pluricelular, unisseriado, com pedicelo formado por 3-4 células e com célula apical alongada e afilada e de paredes espessadas não lignificadas. Esse último tipo de tricoma foi relatado para B. crispa (Cortadi et al., 1999; Budel et al., 2004). Informações contraditórias para B. trimera foram apresentadas por Alquini e Takemori (2000) e Santos-Filho (1979). De acordo com os primeiros autores, os tricomas glandulares foram classificados como tectores, não havendo menção para glandular. Para o último autor, $B$. trimera apresenta tricomas glandulares pluricelulares, cuja célula apical possui formato longo e nitidamente afilado contendo óleo essencial.

É importante ressaltar que a descrição de $B$. trimera na F. Bras. IV (1988-2003) não contempla o tricoma tector observado neste estudo e relata 4 outros tipos de tricomas, a saber, a) pluricelular, unisseriado, ereto, com 3 células no corpo e uma apical cônica, ereta ou inclinada; b) pluricelular, unisseriado, ereto, com 5 células no corpo e uma célula apical cônica, com sua base dilatada; c) pluricelular, unisseriado, com 1-3 células no corpo e célula apical arredondada, globosa, podendo às vezes ser recurvado; e d) pluricelular, unisseriado, recurvado, com 3 células no corpo e uma célula apical globosa e com paredes espessadas.

A organização dos parênquimas fotossintetizantes nas espécies estudadas tem correspondência ao descrito para as alas de B. articulata (Ariza-Espinar, 1973; Cortadi et al., 1999; Ortins, Akisue, 2000), B. crispa (Budel et al., 2004), B. gaudichaudiana (Budel et al., 2003) e B. myriocephala (Sá, Neves, 1996). Todavia foram observados dados conflitantes, como em $B$. trimera foi relatada a presença de estrutura homogênea lacunosa (Chicourel et al., 1997; Jorge et al., 1991), dorsiventral (F. Brás. IV, 2003) e homogênea paliçádica (Cortadi et al., 1999). Esse último tipo também foi relatado para B. crispa (Cortadi et al., 1999).

Dutos secretores são comuns em espécies de Asteraceae e Fahn (1988) descreve que esses podem ter mais de uma camada de células, enquanto que Castro et al. (1997) relatam a presença de dutos circundados por estrato único de células nessa família, e associados exclusivamente ao floema em Baccharis. A ocorrência de dutos secretores no gênero, que têm origem na endoderme, é descrito por Ariza-Espinar (1973) e de acordo com Pagni e Masini (1999), em muitos membros de Asteraceae os dutos estão freqüentemente relacionados com a endoderme, entretanto, quando estão próximos ao floema, os dutos secretores estão associados com o sistema vascular. Nesse aspecto, B. microcephala e $B$. trimera evidenciam dutos secretores com 6-10 células em estrato único, associados à endoderme, características também relatadas em $B$. articulata (Ariza-Espinar, 1973; Cortadi et al., 1999; Ortins, Akisue, 2000), B. crispa (Budel et al., 2004), B. gaudichaudiana (Budel et al., 2003), B. myriocephala (Sá, Neves, 1996) e B. trimera (Alquini, Takemori, 2000). Por outro lado, Cortadi et al. (1999) destacam que os dutos secretores de 
B. crispa não acompanham os feixes vasculares, sendo encontrados apenas nas bordas das alas.

As características observadas no eixo dos cladódios de $B$. microcephala e $B$. trimera, como a distribuição do clorênquima e colênquima, os caracteres da bainha parenquimática e do sistema vascular estão de acordo com diversas espécies de Baccharis (Ariza-Espinar; 1973; SantosFilho, 1979; Jorge et al., 1991; Sá, Neves, 1996; Cortadi et al., 1999; Alquini, Takemori, 2000; Ortins, Akisue, 2000; Budel et al., 2003, 2004; F. Bras. IV, 1988-2003).

Quanto à tipologia dos cristais de oxalato de cálcio, na região perimedular de $B$. microcephala observa-se a presença de cristais de oxalato de cálcio do tipo piramidal, enquanto que os cristais em $B$. trimera mostram-se piramidais e prismáticos de diferentes dimensões. Cristais de oxalato de cálcio são amplamente relatados em B. articulata (Ariza-Espinar, 1973; Cortadi et al., 1999; Ortins, Akisue, 2000), B. crispa (Cortadi et al., 1999; Budel et al., 2004), B. gaudichaudiana (Budel et al., 2003), B. myriocephala (Sá, Neves, 1996) e B. trimera (Cortadi et al., 1999; Santos Filho, 1979; F. Bras. IV, 1988-2003). Divergindo da constatação geral, Jorge et al. (1991) afirmam estarem ausentes no gênero Baccharis. Esse fato pode ser explicado por Nakata (2003), que afirma que o crescimento da planta e a baixa concentração de cálcio podem influenciar na quantidade de cristais presentes.

\section{CONCLUSÃO}

A análise anatômica dos tricomas tectores, associada à análise morfológica externa de $B$. microcephala e $B$. trimera, permite a diferenciação das duas espécies analisadas, a saber: B. microcephala apresenta alas mais estreitas comparativamente a $B$. trimera. Os tricomas tectores que terminam em ponta alongada e afilada ocorrem em $B$. microcephala, enquanto que em $B$. trimera esses anexos são encontrados em forma de T. Este tipo não foi descrito para a espécie na F. Bras. IV, o que sugere a complementação da monografia farmacopéica. Adicionalmente, o formato dos cristais de oxalato de cálcio auxilia na identificação microscópica das espécies individualmente, uma vez que B. microcephala os apresenta na forma piramidal e em $B$. trimera ocorrem também prismáticos de diferentes tamanhos.

\section{AGRADECIMENTOS}

Os autores agradecem ao taxonomista Prof. Dr. Nelson I. Matzenbacher pela identificação das espécies e ao Centro de Microscopia Eletrônica da Universidade Federal do Paraná.

\section{REFERÊNCIAS}

ABAD, M. J.; BERMEJO, P.; GONZALES, E.; IGLESIAS, I.; IRURZUN, A.; CARRASCO, L. Antiviral activity of Bolivian plant extracts. Gen. Pharmacol., v.32, n.4, p.499503, 1999(a).

ABAD, M. J.; BERMEJO, P.; SANCHEZ-PALOMINO, S.; CHIRIBOGA, X.; CARRASCO, L. Antiviral activity of some South American medicinal plants. Phytother. Res., v.13, n.2, p.142-146, 1999(b).

ABAD, M. J.; BESSA, A. L.; BALLARIN, B.; ARAGÓN, O.; GONZALES, E.; BERMEJO, P. Anti-inflammatory activity of four Bolivian Baccharis species (Compositae). J. Ethnopharmacol., v.103, n.3, p.338-344, 2006.

ALONSO, J.; DESMARCHELIER, C. Plantas medicinales autóctonas de la Argentina - bases científicas para su aplicación en atención primaria de la salud. Buenos Aires: Fitociencia, 2006. 663p.

ALQUINI, Y.; TAKEMORI, N. K. Organização estrutural de espécies vegetais de interesse farmacológico. Curitiba: Herbarium, 2000. 79p.

ARIZA-ESPINAR, L. Las especies de Baccharis (Compositae) de Argentina Central. Bol. Acad. Nac. Ciênc., Córdoba, v.50, n.1, p.176-305, 1973.

AVANCINI, C. A. M.; WIEST, J. M.; MUNDSTOCK, E. Bacteriostatic and bactericidal activity of the Baccharis trimera (Less.) DC. - Compositae, decocto, as desinfectant or antisseptic. Arq. Bras. Med. Vet. Zootec., v.52, n.3, p.230234,2000 .

BAGGIO, C. H.; FREITAS, C. S.; RIECK, L.; MARQUES, M. C. A. Gastroprotective effects of a crude extract of Baccharis illinita DC. in rats. Pharmacol. Res., v.47, n.1, p.93-98, 2003.

BARROSO, G. M. Compositae - Subtribo Baccharidinae Hoffmann - Estudo das espécies ocorrentes no Brasil. Rodriguésia, v.28, n.40, p.1-273, 1976.

BARRoso, G. M.; BUENO, O. Compostas: subtribo Baccharidinae. Itajaí: Herbário Barbosa Rodrigues, 2002. 1065 p.

BERLYN, G. P.; MIKSCHE, J. P. Botanical microtechnique and cytochemistry. Ames: Iowa State University, 1976. 326p. 
BIANCHI, N. R.; SILVA, M. O.; SPIASSI, L.; BERGONCI, J. I., MACHADO, C. A. Ensaio de toxicidade excessiva e screening fitoquímico de algumas espécies do gênero Baccharis L. (Asteraceae). Rev. Bras. Farm., v.74, n.3, p.79-80, 1993.

BONA, C. M.; BIASI, L. A.; NAKASHIMA, T.; ZANETTE, F.; CORRÊA-JÚNIOR, C. Carqueja: Cultive esta idéia. Curitiba: SEAB-PR, 2002. 18p.

BRITO, C. J. F. A.; ALQUINI, Y. A new method for staining botanical material embedded in glycol methacrylate (GMA). Arq. Biol. Tecnol., v.39, n.4, p.949-951, 1996.

BUDEL, J. M.; DUARTE, M. R.; SANTOS, C. A. M. Caracteres morfo-anatômicos de Baccharis gaudichaudiana DC., Asteraceae. Acta Farm. Bonaerense, v.22, n.4, p.313-320, 2003a.

BUDEL, J. M.; DUARTE, M. R.; SANTOS, C. A. M.; CUNHA, L. M. Macro and microscopical identification of four species of Baccharis from Trimera group. Rev. Bras. Farmacogn., v.13, n.2, p.42-43, 2003 b.

BUDEL, J. M.; DUARTE, M. R.; SANTOS, C. A. M. Morfoanatomia foliar e caulinar de Baccharis dracunculifolia DC., Asteraceae. Acta Farm. Bonaerense, v.23, n.4, p.477483, 2004a.

BUDEL, J. M.; DUARTE, M. R.; SANTOS, C. A. M. Stem morpho-anatomy of Baccharis cylindrica (Less.) DC., Asteraceae. Rev. Bras. Ciênc. Farm., v.40, n.1, p.93-99, $2004 b$.

BUDEL, J. M.; DUARTE, M. R.; SANTOS, C.A. M.; FARAGO, P. V.; MATZENBACHER, N. I. O progresso da pesquisa sobre o gênero Baccharis, Asteraceae: I - estudos botânicos. Rev. Bras. Farmacogn., v. 15, n. 3, p. 268-271, 2005.

BUDEL, J. M.; MATZENBACHER, N. I; DUARTE, M. R. Genus Baccharis (Asteraceae): a review of chemical and pharmacological studies. In: SINGH, V. K; GOVIL, J. N.. (Orgs.). Recent Progress in Medicinal Plants Phytopharmacology and Therapeutic Values. 3 ed. Houston: Studium Press LLC, 2008. v. 21, p. 1-18.

CASTRO, M. M.; LEITÃO-FILHO, H. F.; MONTEIRO, W. R. Utilização de estruturas secretoras na identificação dos gêneros de Asteraceae de uma vegetação de cerrado. Rev. Bras. Bot., v. 20, n. 2, p.163-174, 1997.
CHICOUREL, E. L.; PIMENTA, D. S.; JORGE, L. I. F.; FERRO, V. O. Contribuição ao conhecimento analítico de três compostas medicinais. Rev. Bras. Farmacogn., v. 7/8, n. 1/2, p. 59-66, 1997.

CIFUENTE, D. A.; SIMIRGIOTIS, M.; FAVIER, L. S.; ROTELLI, A. E.; PELZER, L. E. Anti-inflammatory activity from aerial parts of Baccharis medullosa, Baccharis rufescens and Laennecia sophiifolia in mice. Phytoter. Res., v. 15, n. 6, p. 529-531, 2001.

CORRÊA, M. P. Dicionário das plantas úteis do Brasil e das exóticas cultivadas. Rio de Janeiro: IBDF, 1984. v.2, $707 \mathrm{p}$.

CORTADI, A.; DI-SAPIO, O.; McCARGO, J.; SCANDIZZI, A.; GATTUSO, S.; GATTUSO, M. Anatomical studies of Baccharis articulata, Baccharis crispa and Baccharis trimera, "Carquejas" used in folk medicine. Pharm. Biol., v.37, n.5, p.357-365, 1999.

DUKE, S. O.; PAUL, R. N. Development and fine structure of the glandular trichomes of Artemisia annua L. Int. J. Plant Sci., v.154, n.1, p.107-118, 1993.

FAHN, A. Secretory tissues in vascular plants. New Phytol., v.108, n. 3, p. 229-257, 1988.

FARMACOPÉIA Brasileira. 4 ed. São Paulo: Atheneu, 19882003. 1320p.

FEDER, N.; O'BRIEN, T. P. Plant microthecnique: some principles and new methods. Am. J. Bot., v. 55, n.1, p.123$142,1968$.

FERESIN, G. E.; TAPIA, A.; LÓPEZ, S. N.; ZACCHINO, S. A. Antimicrobial activity of plants used in tradicional medicine of San Juan province, Argentine. J. Ethnopharmacol., v. 78, n.1, p.103-107, 2001.

FOSTER, A. S. Practical plant anatomy. 2. ed. Princeton: D. Van Nostrand, 1949. 228p.

GENE, R. M.; MARIN, E.; ADZET, T. Anti-inflammatory effect of aqueous extracts of three species of the genus Baccharis. Planta Med., v. 58, n. 6, p. 565-566, 1992. 
GIANELLO, J. C.; CEÑAL, J. P.; GIORDANO, O. S.; TONN, C. E.; PETENATTI, M. E.; PETENATTI, E. M.; DEL VITTO, L. A. Medicamentos herbários en el centro-oeste argentino. II. "Carquejas": control de calidad de las drogas oficiales y sustituyentes. Acta Farm. Bonaerense, v.19, n.2, p. 99-103, 2000.

HERAS, B.; SLOWING, K.; BENEDÍ, J.; CARRETERO, E.; ORTEGA, T.; GÓMEZ-SERRANILLOS, P.; LISO, P. A.; VILLAR, A.; CIRIBORA, X. Anti-inflammatory and antioxidant activity of plants used in traditional medicine in Ecuador. J. Ethnopharmacol., v.61, n.2, p.161-166, 1998.

JANUÁRIO, A. H.; SANTOS, S. L.; MARCUSSI, S.; MAZZI, M. V.; PIETRO, R. C. L. R.; SATO, D. N.; ELLENA, J.; SAMPAIO, S. V.; FRANÇA, S. C.; SOARES, S. M. Neo-clerodane diterpenoid, a new metalloprotease snake venom inhibitor from Baccharis trimera (Asteraceae): anti-proteolytic and anti-hemorrhagic properties. Chem. Biol. Interact., v.150, n.3, p.243-251, 2004.

JOHANSEN, D. A. Plant microtechnique. New York: McGraw Hill Book, 1940. 523p.

JORGE, L. I. F.; PEREIRA, U.; SILVA, A. M. Identificação histológica das principais compostas brasileiras de emprego medicinal. Rev. Inst. Adolfo Lutz, v.51, n.1/2, p.47-51, 1991.

JUDD, W. S.; STEVENS, P. F.; CAMPBELL, C. S.; KELLOGG, E. A. Plant systematics: a phylogenetic approach. Sunderland: Sinauer, 1999. 464p.

METCALFE, C. R.; CHALK, L. Anatomy of the dicotyledons. Oxford: Clarendon Press, 1988. v.1, 276p.

METCALFE, C. R.; CHALK, L. Anatomy of the dicotyledons: leaves, stem, and woods in relation to taxonomy with notes on economic uses. Oxford: Clarendon Press, 1950. v.2, 1500 p.

MONGELLI, E.; DESMARCHELIER, C.; TALOU, J. R.; COUSSIO, J.; CICCIA, G. In vitro antioxidant and cytotoxicity activity of extracts of Baccharis coridifolia DC. J. Ethnopharmacol., v.58, n.3, p.157-163, 1997.

MONTEIRO, W. R.; MARÍLIA, M. C.; MAZZONI-VIVEIROS, S. C.; MAHLBERG, P. G. Development and some histochemical aspects of foliar glandular trichomes of Stevia rebaudiana (Bert.) Bert. - Asteraceae. Rev. Bras. Bot., v.24, n.3, p.349-357, 2001.
MORS, W. B.; RIZZINI, C. T.; PEREIRA, N. A. Medicinal plants of Brazil. Michigan: Reference Publications, 2000. $501 \mathrm{p}$.

MUSCHIETTI, L.; MARTINO, V.; FERRARO, G.; COUSSIO, J.; SEGURA, S.; CARTAÑA, C.; CAÑIGUERAL, S.; ADZET, T. The anti-inflammatory effect of some species from South America. Phytother. Res., v.10, n.1, p.84-86, 1998.

NAKATA, P. A. Advances in our understanding of calcium oxalate crystal formation and function in plants. Plant Sci., v.164, n.6, p.901-909, 2003.

O’BRIEN, T. P., FEDER, N.; MCCULLY, M. E. Polychromatic staining of plant cell walls by toluidine blue O. Protoplasma, v.59, n.2, p.368-373, 1964.

OLIVEIRA, F.; AKISUE, G. Fundamentos de farmacobotânica. 2 ed. São Paulo: Atheneu, 1997. 216p.

OLIVEIRA, V. C.; BASTOS, E. M. Aspectos morfo-anatômicos da folha de Baccharis dracunculifolia DC. (Asteraceae) visando a identificação da origem botânica da própolis. Acta Bot. Bras., v.12, n.3, p.431-439, 1998.

OLIVEIRA, S. Q.; DAL-PIZZOL, F.; GOSMANN, G.; GUILLAUME, D.; MOREIRA, J. C.; SCHENKEL, E. P. Antioxidant activity of Baccharis articulata extracts: isolation of a new compound with antioxidant activity. Free Radical Res., v.37, n.5, p.555-559, 2003.

OLIVEIRA, A. C. P.; ENDRINGER, D. C.; AMORIM, L. A. S.; BRANDÃO, M. G. M.; COELHO, M. M. Effect of the extracts and fractions of Baccharis trimera and Syzygium cumini on glycaemia of diabetic and non-diabetic mice. $J$. Ethnopharmacol., v.102, n.3, p.465-469, 2005.

ORTINS, G. M. M.; AKISUE, G. Estudo morfo-histológico, screening fitoquímico, constantes físicas e análise cromatográfica da droga e extrato fluido visando controle de qualidade da espécie Baccharis articulata Pers. Lecta, v.18, n.2, p.9-32, 2000.

PAGNI, A. M.; MASINI, A. Morphology, distribution and histochemistry structures in vegetative organs of Santolina leucantha Bertol. (Asteraceae). Israel J. Plant Sci., v.49, n.4, p.257-263, 1999.

ROESER, K. R. Die Nadel der Schwarzkiefer-Massenprodukt und Kunstwerk der Natur. Mikrokosmos, v.61, n.2, p.33-36, 1972. 
RODRIGUEZ, E., HEALEY, P. L., MEHTA, I. Biology and chemistry of plant trichomes. New York: Plenum Press, 1984. p.71-94.

ROSAS-ROMERO, A.; SAAVEDRA, G. Screening of Bolivian plants for antioxidant activity. Pharm. Biol., v.43, n.1, p.79-86, 2005.

SÁ, M. F. A.; NEVES, L. J. Contribuição ao estudo das plantas medicinais Baccharis myriocephala DC. Rev. Bras. Farm., v.77, n.3, p.88-96, 1996.

SANCHEZ-PALOMINO, S.; ABAD, M. J.; BEDOVA, L. M.; GARCIA, J.; GONZALES, E.; CHIRIBOGA, X.; BERMEJO, P.; ALCAMI, J. Screening of South American plants against human immunodeficiency virus: preliminary fractionation of aqueous extract from Baccharis trinervis. Biol. Pharm. Bull., v.25, n.9, p.1147-1150, 2002.

SANTOS-FILHO, D.; SARTI, S. J.; VICHNEWSKI, W.; BULHÕES, M. S.; LEITÃO-FILHO, H. F. Atividade moluscicida em Biomphalaria glabrata, de uma lactona diterpênica e de uma flavona isoladas de Baccharis trimera (Less.) A.P. De Candole. Rev. Fac. Farm. Odontol. Ribeirão Preto, v.17, n.1, p.43-47, 1980.

SASS, J. E. Botanical microtechnique. 2. ed. Ames: Iowa State College, 1951. 228p.

SILVA, J. B.; GROTTA, A. S. Anatomia da folha e óleo essencial de Baccharis retusa DC., Compositae. Rev. Farm. Bioquím. USP, v.9, n.2, p.321-326, 1971.

SIMÕES-PIRES, C.A.; DEBENEDETTI, S.; SPEGAZZINI, E.; MENTZ, L.A.; MATZENBACHER, N.I.; LIMBERGER, R.P.; HENRIQUES, A.T. Investigation of the essential oil from eight species of Baccharis belonging to sect. Caulopterae (Asteraceae, Astereae): a taxonomic approach. Plant Syst. Evol., v.253, n.1, p.23-32, 2005.

SIMÕES-PIRES, C. A.; QUEIROZ, E. F.; HENRIQUES, A. T.; HOSTETTMANN, K. Isolation and on-line identification of antioxidant compounds from three Baccharis species by HPLC-UV-MS/MS with post-column derivatisation. Phytochem. Anal., v.16, n.5, p.307-314, 2005.
SOBOTKA, A. M.; LANGELOH, A.; SCHENKEL, E. P. Efeito dos extratos aquosos de Baccharis ochracea Spreng. e Iodina rhombifolia Hook. et Arn. sobre a reprodução de ratas. Rev. Bras. Ciênc. Farm., v.17, n.1, p.147-153, 1996.

SOICKE, H.; LENG-PESCHLOW, E. Characterization of flavonoids from Baccharis trimera and their antihepatotoxic properties. Planta Med., v.53, n.1, p.37-39, 1987.

SOUZA, W. Técnicas básicas de microscopia eletrônica aplicadas às Ciências Biológicas. Rio de Janeiro: Sociedade Brasileira de Microscopia Eletrônica, 1998. 179p.

TAPIA, A.; RODRIGUEZ, J.; THEODULOZ, C.; LOPEZ, S.; FERESIN, G. E.; SCHMEDA-HIRSCHMANN, G. Free radical scavengers and antioxidants from Baccharis grisebachii. J. Ethnopharmacol., v.95, n.2/3, p.155-161, 2004.

TORTORIELLO, J.; AGULAR-SANTAMARÍA, L. Evaluation of the calcium-antagonist, antidiarrhoeic and central nervous system activities of Baccharis serraefolia. J. Ethnopharmacol., v.53, n.3, p.157-163, 1996.

VERÁSTEGUI, M. A.; SÁNCHEZ, C. A.; HEREDIA, N. L.; GARCÍA-ALVARADO, J. S. Antimicrobial activity of extracts of three major plants from the Chihuahuan desert. J. Ethnopharmacol., v.52, n.3, p.175-177, 1996.

VERDI, L. G.; BRIGHENTE, M. C.; PIZZOLATTI, M. G. Gênero Baccharis (ASTERACEAE): Aspectos químicos, econômicos e biológicos. Quim. Nova, v.28, n.1, p.85-94, 2005.

WATANABE, T. M. Caracterização farmacognóstica de espécies de Baccharis comercializadas como carquejas. Rev. Racine, v.15, n.1, p.90-95, 2005.

WERKER, E. Trichome diversity and development. Adv. Bot. Res., v.31, n.1, p.1-35, 2000.

Recebido para publicação em 14 de novembro de 2007. Aceito para publicação em 07 de novembro de 2008. 